\title{
An Experimental Test of the Dose-Dependent Effect of Carotenoids and Immune Activation on Sexual Signals and Antioxidant Activity
}

\author{
Carlos Alonso-Alvarez, ${ }^{1, *}$ Sophie Bertrand, ${ }^{1, \dagger}$ Godefroy Devevey, ${ }^{2, \star}$ Maria Gaillard, ${ }^{2, \$}$ Josiane Prost, ${ }^{3, \|}$ \\ Bruno Faivre, ${ }^{2, \#}$ and Gabriele Sorci $i^{\text {,**}}$
}

\begin{abstract}
1. Laboratoire de Parasitologie Evolutive, Centre National de la Recherche Scientifique, Unité Mixte de Recherche 7103, Université Pierre et Marie Curie, 7 quai St. Bernard, CC237, 75252 Paris Cedex 05, France;

2. Université de Bourgogne, Centre National de la Recherche Scientifique, Unité Mixte de Recherche 5561, BioGéoSciences, Equipe Ecologie Evolutive, 6 Boulevard Gabriel, 21000 Dijon, France;

3. Université de Bourgogne, Unité Propre de Recherche de l'Enseignement Supérieur Lipides Nutrition, EA 2422, 6 Boulevard Gabriel, 21000 Dijon, France
\end{abstract}

Submitted March 10, 2004; Accepted July 2, 2004;

Electronically published September 29, 2004 and immune activation affected the amount of circulating plasma carotenoids, the beak color, and the antioxidant defenses (assessed as the resistance of red blood cells to a controlled free radical attack). Carotenoid availability affected the amount of circulating carotenoids and beak color; both variables reached a plateau at the highest carotenoid doses. Immune activation diverted carotenoids from plasma, and this in turn affected the expression of the sexual trait. Finally, we found a positive correlation between the change in circulating carotenoids and antioxidant defenses. These results support the idea that carotenoids have important physiological properties that ensure the honesty of carotenoid-based sexual traits.

Keywords: immune activation, oxidative stress, ornamental coloration, plasma carotenoids, sexual selection, zebra finch.

One of the major goals of studies on sexual selection has been to identify the information content of sexual signals and the mechanisms preventing cheating (Zahavi 1975; Grafen 1990; Espmark et al. 2000). Indeed, if signals do carry information about any aspect of the signaler, the receiver has to trust it if it wants to base its choice on the signal (Wiley 1994). Mate choice is a particularly relevant field of application of this idea because females use male secondary sexual traits to assess the phenotypic and/or genetic quality of their mate (Andersson 1994). So what prevents males from developing unreliable sexual signals? It is now relatively well established that costs associated with either the production or the maintenance of the signal can prevent cheating (Johnstone 1995). However, the currency of these costs is currently still debated and probably depends on the nature of the signal involved.

Many animals harbor brightly colored patches of skin or feathers. Carotenoids have been identified as the main pigments involved in the expression of yellow to red sexual signals in fish and birds (Olson and Owens 1998). These pigments cannot be synthesized by vertebrates and have to be ingested with food. For this reason, carotenoid-based sexual signals have been considered good examples of honest signaling because they might reliably reflect individual
Am. Nat. 2004. Vol. 164, pp. 651-659. (C) 2004 by The University of Chicago. 0003-0147/2004/16405-40332\$15.00. All rights reserved. 
ability to find high-quality food (Endler 1980; Hill 1990; Grether et al. 1999; but see Hudon 1994). Of course, this is based on the implicit assumptions that carotenoids are limiting and/or that all individuals do not have the same carotenoid assimilation efficiency (Craig and Foote 2001). More recently, taking advantage of the literature on nutrition and health, evolutionary biologists emphasized that the honesty of carotenoid-based signals might also be reinforced because carotenoids have many functions (Lozano 1994; Hill 1999; von Schantz et al. 1999). Indeed, beyond their role in the expression of colored signals, they also have immunomodulatory and antioxidant properties (Burton 1989; Chew 1993). Individuals that invest carotenoids in sexual signaling could not do so without diverting them from the immune and the detoxification system (Lozano 1994).

Recently, these ideas have received experimental support. Male blackbirds (Turdus merula) have an orange to yellow beak that is used in intra- and possibly intersexual interactions (Faivre et al. 2001; Bright and Waas 2002). Beak color appears to be due to carotenoids (Faivre et al. 2003). By activating the immune system with an injection of sheep red blood cells, Faivre et al. (2003) were able to show that males exposed to the antigen exhibited a change in beak color from orange to yellow. This result suggests a trade-off between carotenoids used for the expression of the signal and carotenoids used by the immune system. In agreement with this view, recent studies in birds (Blount et al. 2003; McGraw and Ardia 2004) and fish (Grether et al. 2004) have shown that supplementing carotenoids results in enhanced expression of both sexual signals and immune response in males.

In spite of these recent advances, we still lack an integrated and comprehensive view of the action of carotenoids on sexual signaling, immune functioning, and free radical scavenging. Here, we performed an experiment with zebra finches. Males of this species have an orange to red beak that is used by females as a signal in mate choice (Burley and Coopersmith 1987; Blount et al. 2003; but also see Collins and ten Cate 1996). Females have an orange beak, but it is not known whether males use female beak color to choose a mate. We assigned males and females to six groups that received an increasing dose of carotenoids in the drinking water. Furthermore, within each carotenoid group, we repeatedly activated the immune system of half of the birds with lipopolysaccharide (LPS) of Escherichia coli, whereas the other half was used as a control (injected with phosphate buffered saline [PBS]). LPS induces an inflammatory response by nonspecifically activating a wide array of cells, including macrophages and heterophils, only a few hours after exposure (Janeway and Travers 1999). The inflammatory response is followed by the production of anti-LPS antibodies (Pox- ton 1995; Janeway and Travers 1999). Interestingly, cells of the innate immune response release nitric oxide (NO) to fight off the invading pathogen (here simulated by the LPS injection). NO is a free radical that has a damaging effect on the pathogen and potentially also on host cells and molecules (Ahmad 1995).

With this experimental design, we were therefore able to address the following questions: How does the level of carotenoid availability affect beak color? Do females allocate carotenoids to beak color in the same way as do males? Does immune activation divert carotenoids from plasma and sexual signals in a dose-dependent way? Does increased carotenoid availability enhance antioxidant defenses?

\section{Methods}

\section{General Procedure}

This study was carried out on a zebra finch population ( $N=120$ individuals) housed in indoor facilities. Birds were maintained in individual cages $(0.6 \mathrm{~m} \times 0.4$ $\mathrm{m} \times 0.4 \mathrm{~m}$ ) for the duration of the experiment (28 days), under constant temperature $\left(21^{\circ} \mathrm{C}\right.$, to the nearest $\left.1^{\circ} \mathrm{C}\right)$ and photoperiod (13L : 11D). Food (a commercial mix of seeds for exotic birds mainly composed of millet and canary grass seed) was provided ad lib. Two birds of the same sex were kept per cage with a separation in the middle to ensure that each bird was isolated.

Blood samples and a digital picture of the bill were taken twice for each bird during the experiment (day 0 and day 28). Body mass (to the nearest $0.1 \mathrm{~g}$ ) was also measured at day 0 and day 28. Pictures were taken with a digital camera (NV-MX7EG, Osaka) in a standardized way with a Repro lighting unit (Kaiser Fototechnik, Buchen). The color of the bill was analyzed with the Sigma Scan Pro software (SPSS, Chicago). Hue (i.e., redness, expressed as the angle of the color wheel) of the upper surface of the bill was determined as the mean value of 10 measurements (10 randomly selected points) taken by the same person (S.B.) blindly with respect to the treatment of each individual. This color parameter (low values of hue indicate redder color) has already been extensively used to measure variation in bill color in zebra finches (Burley et al. 1992; Birkhead et al. 1998; Blount et al. 2003). Blood samples $(\sim 100 \mu \mathrm{L})$ were collected from the brachial vein using heparinized capillaries. Afterward, samples were centrifuged, and the plasma was separated and stored at $-20^{\circ} \mathrm{C}$.

\section{Manipulation of Carotenoid Availability}

Ten males and 10 female zebra finches were randomly distributed to six groups of increasing carotenoid avail- 
Table 1: ANCOVA on change in plasma concentration of total carotenoids between the start and the end of the experiment (value at day 28 minus value at day 0 )

\begin{tabular}{lrrr}
\hline Source of variation & df & \multicolumn{1}{c}{$F$} & $P$ \\
\hline Sex & 1,95 & 1.47 & .228 \\
Immune treatment & 1,95 & 8.64 & .0041 \\
Carotenoid dose in the water & 1,95 & 35.51 & $<.0001$ \\
$\begin{array}{l}\text { Squared carotenoid dose in } \\
\quad \text { the water }\end{array}$ & 1,95 & 15.28 & .002 \\
$\begin{array}{l}\text { Sex } \times \text { squared carotenoid } \\
\quad \text { dose in the water }\end{array}$ & 1,95 & 5.07 & .0266 \\
\hline $\begin{array}{l}\text { Note: Sex and immune treatment are factors, and carotenoid dose } \\
\text { in the drinking water and its squared term are covariates. }\end{array}$
\end{tabular}

ability. Birds assigned to the first level were provided with only water and therefore were considered as controls. Birds in the other five groups received 12.5, 25, 50, 100, and $200 \mu \mathrm{g} / \mathrm{mL}$ of carotenoids diluted in the drinking water, respectively (Oro Glo liquid, $11 \mathrm{mg} / \mathrm{mL}$ lutein and zeaxanthin [20:1,w/w]; Kemin France SRL, Nantes). All drinks were freshly prepared each day using cool water and were provided in opaque dispensers in order to avoid oxidation (Blount et al. 2003). Lutein and zeaxanthin are the most abundant carotenoids in the diet of captive zebra finches, representing more than $90 \%$ of all dietary carotenoids (McGraw et al. 2002).

\section{Activating the Immune System}

Within each carotenoid group, birds were randomly assigned to two immune activation treatments. Half of the birds (five males and five females per carotenoid group) were injected intraperitoneally with $0.01 \mathrm{mg}$ of LPS from the cell wall of Escherichia coli (serotype O55:B5; SIGMA, St. Louis) diluted in $0.1 \mathrm{~mL}$ of PBS (concentration = $0.1 \mathrm{mg} / \mathrm{mL}$ ). The other half was used as a control and injected with the same volume $(0.1 \mathrm{~mL})$ of PBS. In order to maintain the immune challenge during the 4 weeks of the experiment, birds were injected once per week.

\section{Measuring Plasma Carotenoids}

Twenty microliters of plasma was diluted in $180 \mu \mathrm{L}$ of absolute ethanol. The dilution was mixed in a vortex, and the flocculent protein was precipitated by centrifuging the sample at 1,500 g for $10 \mathrm{~min}$. We examined the supernatant in a spectrophotometer and determined the optical density of the carotenoid peak at $450 \mathrm{~nm}$. Carotenoid concentration was determined from a standard curve of lutein. All samples from the same individual were analyzed in the same plate. In order to assess the reliability of this technique, high-performance liquid chromatography (HPLC) analyses were also performed on 18 plasma samples and were compared with colorimetric measurements. HPLC determined the presence of four carotenoids in the plasma of zebra finches (lutein, zeaxanthin, anhydrolutein, and $\beta$ cryptoxanthin; see also McGraw et al. 2002). The total amounts of carotenoids determined by the two techniques were highly correlated $(r=0.95, n=18, P<.0001)$. Therefore, our colorimetric measurements can be considered as representative of total plasma carotenoid concentration.

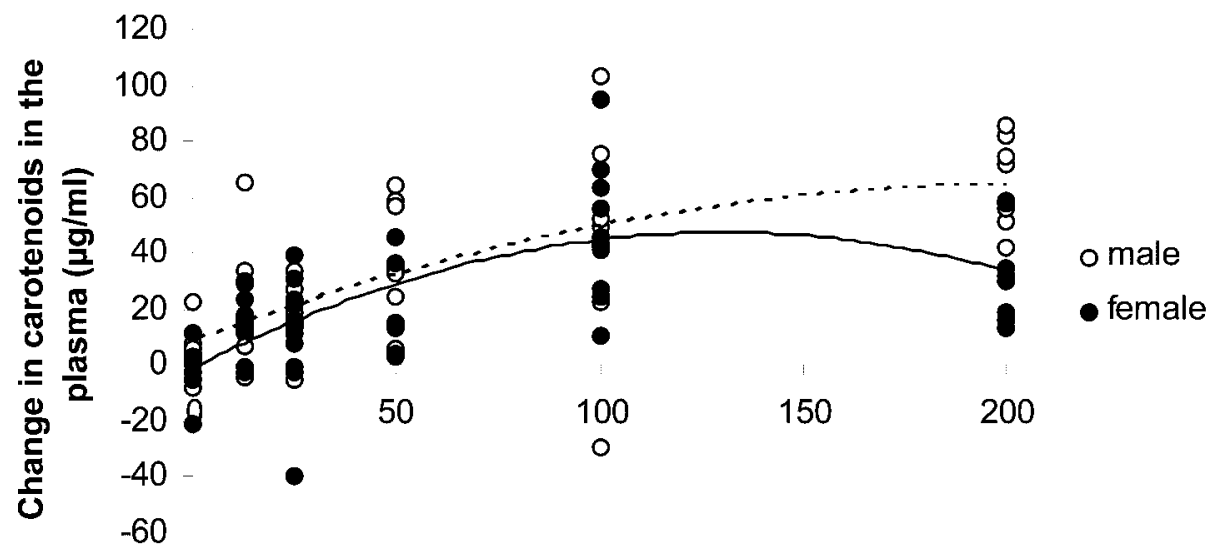

\section{Carotenoids in the drinking water $(\mu \mathrm{g} / \mathrm{ml})$}

Figure 1: Relationship between change in plasma carotenoids during the 4 weeks of the experiment and the concentration of carotenoids in the drinking water for male (open circle, dotted line) and female (filled circle, solid line) zebra finches. 


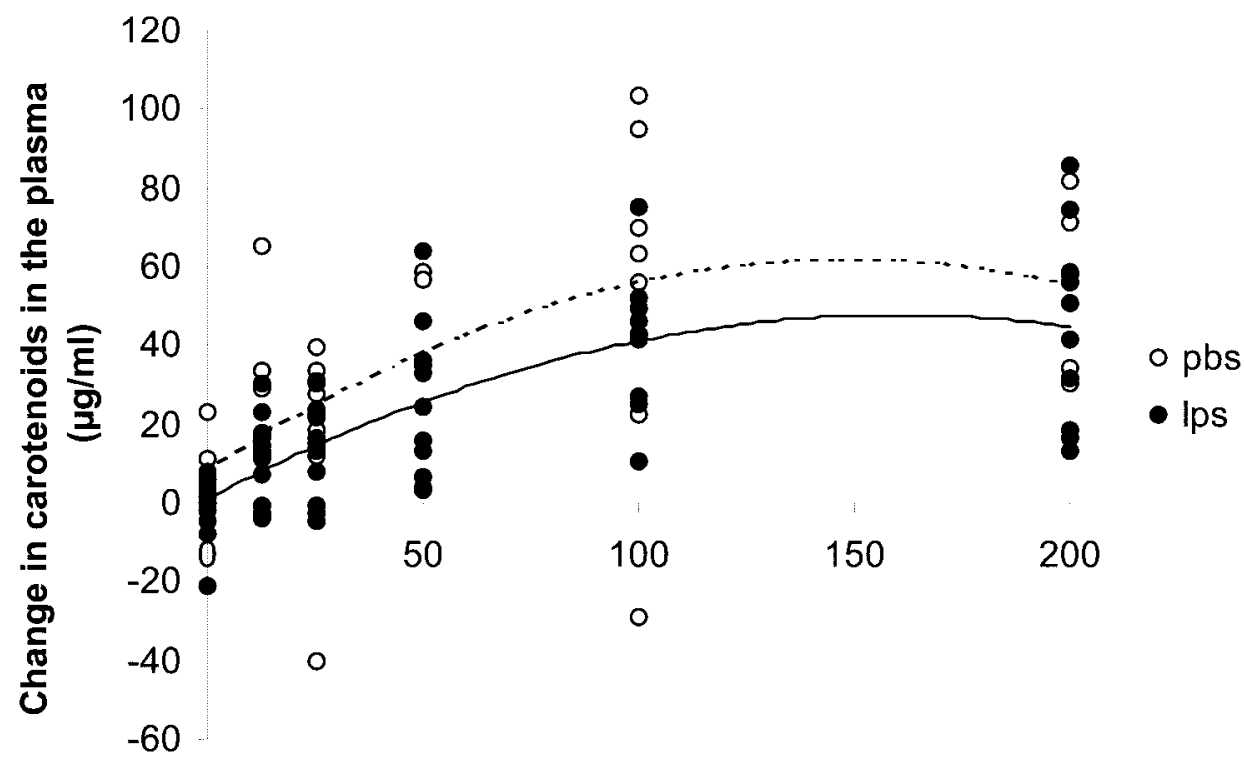

Carotenoids in the drinking water $(\mu \mathrm{l} / \mathrm{ml})$

Figure 2: Relationship between change in plasma carotenoids during the 4 weeks of the experiment and the concentration of carotenoids in the drinking water for zebra finches injected with lipopolysaccharide (filled circle, solid line) or with phosphate buffered saline (open circle, dotted line).

\section{Assessment of Global Antioxidant Defenses}

A subsample of whole blood taken from day 28 was used to assess total antioxidant defenses. This was done by measuring the time needed to hemolyze $50 \%$ of the red blood cells exposed to a controlled free radical attack. We used the KRL test (Brevet Spiral V02023, Couternon; http:// www.nutriteck.com/sunyatakrl.html) adapted to bird physiological parameters (osmolarity, temperature; see also Alonso-Alvarez et al. 2004). The principle of the test is to submit whole blood to a thermocontrolled free radical aggression (2,2'-azobis-(aminodinopropane) hydrochloride [AAPH]; Rojas Wahl et al. 1998). All families of free radical scavengers present in the blood are mobilized to fight off the oxidant attack (Pieri et al. 1996; Girodon et al. 1997; Lesgards et al. 2002; Stocker et al. 2003). Twenty microliters of blood was immediately diluted in $730 \mu \mathrm{L}$ of KRL buffer $\left(150 \mathrm{mM} \mathrm{Na}^{+}, 120 \mathrm{mM} \mathrm{Cl}^{-}, 6 \mathrm{mM} \mathrm{K}^{+}, 24\right.$ $\mathrm{mM} \mathrm{HCO}_{3}^{-}, 2 \mathrm{mM} \mathrm{Ca}^{2+}, 340 \mathrm{mOsm}, \mathrm{pH}$ 7.4). Samples were stored at $4^{\circ} \mathrm{C}$ before analysis, which occurred within $24 \mathrm{~h}$ of collection. Eighty microliters of KRL-diluted blood was incubated at $40^{\circ} \mathrm{C}$ with $136 \mu \mathrm{L}$ of a $150-\mathrm{mM}$ solution of AAPH. The lysis of red blood cells was assessed with a microplate reader device, which measures the decrease of optical density at the wavelength of $540 \mathrm{~nm}$.

\section{Statistical Procedures}

ANCOVA models were used to analyze changes in plasma carotenoid concentration, beak color, body mass (value at day 28 minus value at day 0), and antioxidant defenses (at day 28). The independent variables included two factors (sex and immune treatment) and two covariates (the carotenoid dose and the squared carotenoid dose). This last term was added to appraise the possible nonlinear relationship between dependent variables and carotenoid availability. All the two-way interactions were also included in the model and were subsequently removed if not significant $(P>.05)$.

Differences in sample sizes reflect missing values due to, for instance, reduced blood volume. All the statistical analyses were performed using SAS software (SAS Institute 2001).

Table 2: ANCOVA on change in bill color (hue) between the start and the end of the experiment (value at day 28 minus value at day 0 )

\begin{tabular}{lcrc}
\hline Source of variation & $\mathrm{df}$ & \multicolumn{1}{c}{$F$} & $P$ \\
\hline Sex & 1,114 & 9.38 & .0027 \\
Immune treatment & 1,114 & 3.66 & .0583 \\
Carotenoid dose in the water & 1,114 & 10.42 & .0016 \\
$\begin{array}{l}\text { Squared carotenoid dose in } \\
\quad \text { the water }\end{array}$ & 1,114 & 5.26 & .0237 \\
\hline
\end{tabular}

Note: Sex and immune treatment are factors, and carotenoid dose in the drinking water and its squared term are covariates. 

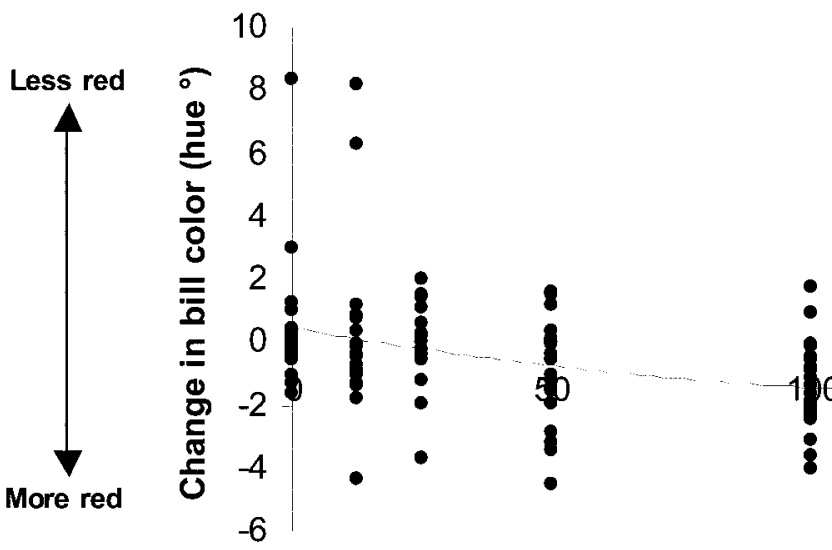

150

\section{Carotenoids in the drinking water $(\mu \mathrm{g} / \mathrm{ml})$}

Figure 3: Relationship between change in bill color (hue) during the 4 weeks of the experiment and the concentration of carotenoids in the drinking water.

Results

\section{Initial Values}

Male zebra finches had initially redder bills than did females (males: mean $\pm \mathrm{SE}, 2.91^{\circ} \pm 0.19^{\circ}, n=59$; females: mean $\pm \mathrm{SE}, \quad 7.42^{\circ} \pm 0.32^{\circ}, \quad n=60 ; \quad F=145.8, \quad \mathrm{df}=$ $1,117, P<.0001$ ), but the amount of carotenoids circulating in the plasma was similar for the two sexes (males: mean $\pm \mathrm{SE}, \quad 31.77 \pm 1.85 \mu \mathrm{g} / \mathrm{mL}, \quad n=50$; females: mean $\pm \mathrm{SE}, \quad 29.74 \pm 2.02 \mu \mathrm{g} / \mathrm{mL}, n=52 ; \quad F=0.55$, $\mathrm{df}=1,100, P=.461$ ). Initial values (beak color and plasma carotenoids) of birds in the two immune treatments and the six carotenoid groups were not statistically different (all $P>.10$ ).

\section{Changes in Plasma Carotenoid Concentration}

Carotenoid availability strongly affected levels of circulating carotenoids in the plasma (table 1; fig. 1). The squared carotenoid dose was also statistically significant (table 1), showing that the increase in plasma carotenoids attained a plateau for the highest doses (fig. 1). Patterns of change in carotenoid concentration were similar between sexes, except for the highest carotenoid dose (fig. 1). This resulted in a significant sex by squared carotenoid dose interaction (table 1). Change in plasma carotenoids was equally affected by immune activation (table 1). Birds injected with PBS showed an increase in plasma carotenoid levels that was significantly higher than the increase for LPS-injected birds (fig. 2). Interestingly, the effect of immune activation on plasma carotenoids was independent of carotenoid availability as shown by the nonsignificant immune challenge by carotenoid availability interaction $(P>.5)$.

\section{Changes in Bill Color}

Carotenoid dose and its squared term explained a significant fraction of variance of bill color (table 2). Birds having higher access to carotenoids had a redder beak, but again beak color reached a plateau for the two highest doses (fig. 3). The effect of immune challenge on changes in bill color was at the border of the significance threshold $(P=.058$; table 2$)$. However, when analyzing bill color at the end of the experimental manipulation, LPS birds had significantly less red beaks than did control individuals $(F=5.14$, df $=1,116, P=.025$; fig. 4$)$.

In agreement with the idea that carotenoid availability increased both the amount of circulating carotenoids as well as beak color, we found that the color at the end of the experimental period was predicted by the change in plasma carotenoids for males and females (ANCOVA: sex, $F=37.92, \mathrm{df}=1,98, P<.0001$; change in plasma carotenoids, $F=10.26$, $\mathrm{df}=1,98, P=.0018$; fig. 5 ).

\section{Change in Body Mass}

Body mass remained stable throughout the duration of the experiment (repeated-measures ANOVA: $F=2.02$, $\mathrm{df}=1,112, P=.158)$. Individual variation in body mass was not affected by carotenoid availability, immune treatment, or sex (always $P>.3$ ).

\section{Antioxidant Defenses}

Carotenoid supplementation, immune challenge, and sex had no effect on resistance to oxidative stress (carotenoid dose in the water: $F=0.57$, $\mathrm{df}=1,115, \quad P=.453$; 

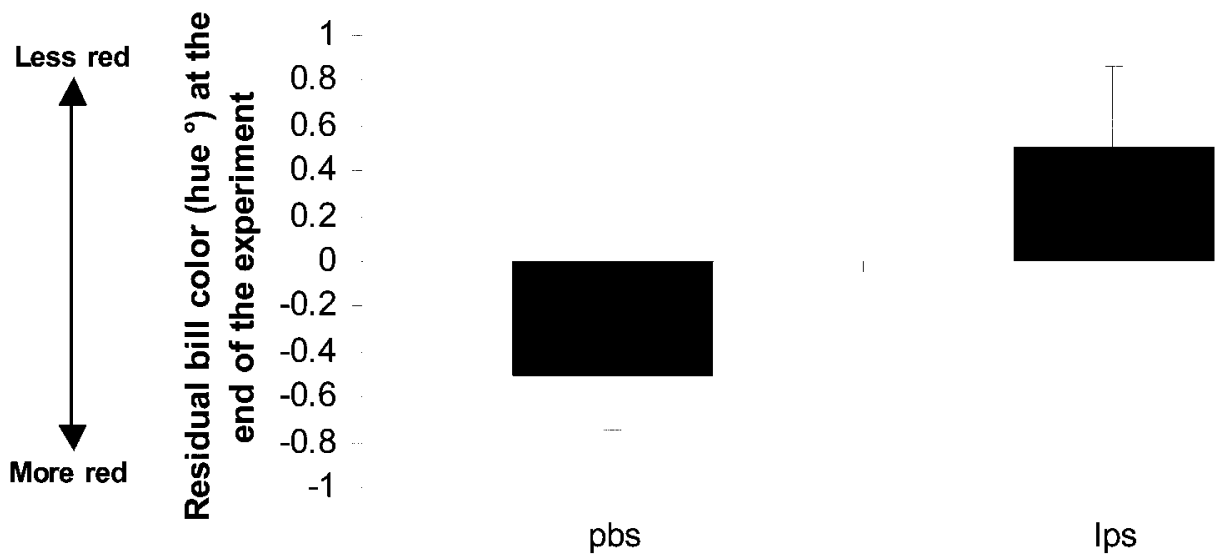

Immune treatment

Figure 4: Effect of immune activation (lipopolysaccharide vs. phosphate buffered saline) on residual bill color at the end of the 4-week experimental period. Residuals were computed from a model with sex, carotenoid concentration in the drinking water, and its squared term. Bars $=$ SE.

squared carotenoid dose: $F=0.19, \mathrm{df}=1,115, \quad P=$ .663 ; immune treatment: $F=1.48$, df $=1,115, P=$ .226 ; sex: $F=2.02$, df $=1,115, P=.158)$. However, antioxidant defenses were positively and significantly correlated with changes in plasma carotenoids during the course of the experiment (slope \pm SE $=0.054 \pm 0.018$, $P=.003$ ); birds with the highest increase in plasma carotenoids exhibited the highest value of resistance to oxidative stress (fig. 6).

\section{Discussion}

We found that carotenoid availability affected in a dosedependent way both levels of plasma carotenoids and bill color. The relationship was not linear, and the amount of plasma carotenoids as well as beak color tended to stabilize for the two highest doses. We also found that sexes differed in their relative allocation of diet carotenoids, at least for the highest doses. Similar to previous recent results, we found that immune activation diverted carotenoids from the plasma (Koutsos et al. 2003) and affected the color of the beak (Faivre et al. 2003), here irrespective of sex or carotenoid availability. Finally, although antioxidant defenses were not directly affected by the experimental supplementation of carotenoids or the immune activation, the change in plasma carotenoids during the course of the experiment was positively correlated with antioxidant defenses.

In the past decade, much emphasis has been put on the potential role carotenoids might play as a reinforcement mechanism for honest sexual signaling in animals (Olson and Owens 1998). Several studies demonstrated that supplementing carotenoids induces a change in the color of traits used in mate choice (Kodric-Brown 1989; Blount et al. 2003; McGraw and Ardia 2004). To our knowledge, this is the first study that investigates the dose-dependent effect of carotenoids on both the amount of pigments circulating in the blood and the amount that is fixed in a secondary sexual trait. Bill color is a sexually selected trait in male zebra finches (Burley and Coopersmith 1987; Blount et al. 2003; but also see Collins and ten Cate 1996); however, the function of female color is still unclear. Although males prefer to mate with females in better condition (Wynn and Price 1993), it is unknown whether they use female beak color to assess female quality.

The dose-dependent approach allowed us not only to test the idea that providing more carotenoids affects the expression of a secondary sexual trait but also to detect a dose beyond which a further increase in carotenoids in the diet does not produce a change in carotenoids circulating in the plasma or mobilized in the beak. These findings show that at high doses, carotenoids are not limiting for the expression of the sexual signal and that the amount of plasma carotenoids is physiologically regulated. Additionally, we found a significant interaction between the sex and the squared carotenoid dose (table 1), reflecting different relative allocation of diet carotenoids, at least for the highest doses (fig. 1). This result is unlikely to be due to sex differences in the allocation of carotenoids to bill color because hue was not affected by the interaction between sex and the carotenoid dose. Alternatively, this might reflect a sex-related difference in the physiological regulation of circulating carotenoids (see McGraw et al. 2003).

The reliability of carotenoid-based sexual signals is not restricted to the ability of individuals to gather these pig- 


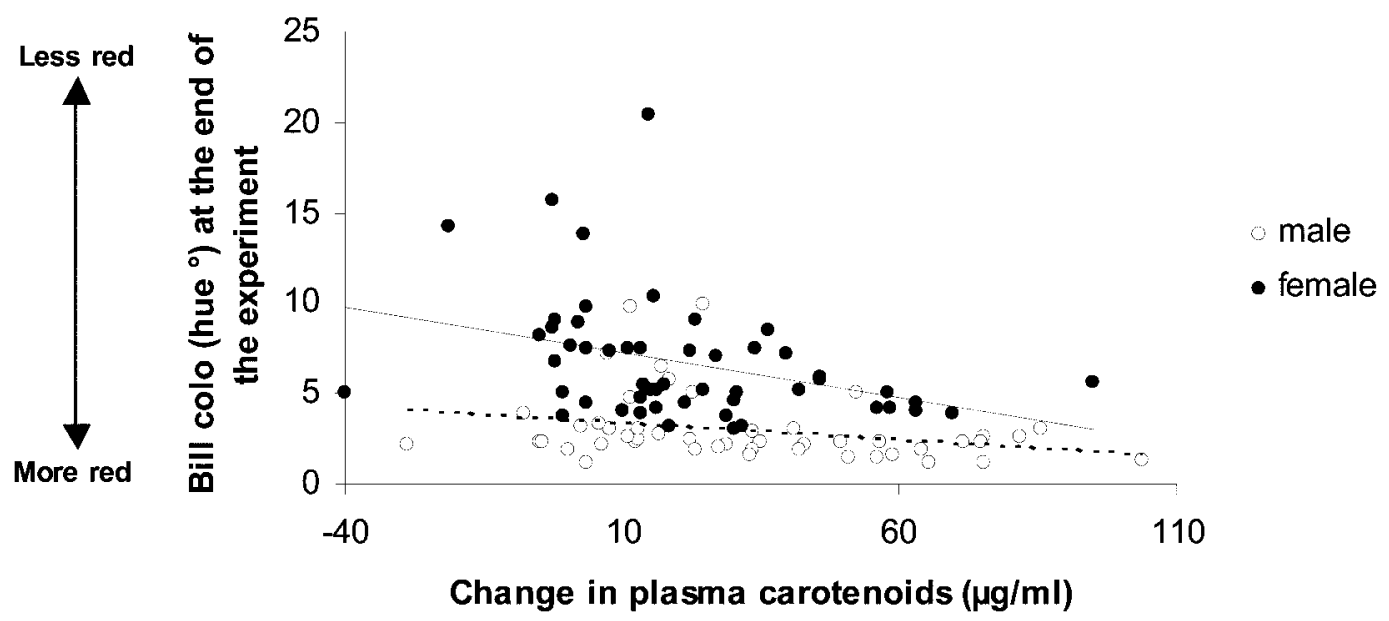

Figure 5: Relationship between bill color (hue) at the end of the 4-week experimental period and change in plasma carotenoids for male (open circle, dotted line) and female (filled circle, solid line) zebra finches.

ments in the diet and assimilate them. At the physiological level, carotenoids are involved in two important functions: the modulation of the immune system and the detoxification of free radicals (Burton 1989; Chew 1993; von Schantz et al. 1999). For this reason, it has been suggested that carotenoid-based signals are honest indicators of individual quality because only high-quality males can allocate significant amounts of these pigments to the sexual signal at the expense of the other functions (Lozano 1994; von Schantz et al. 1999). Experimental support to the trade-off between carotenoid-based traits and immunity has recently been provided (Blount et al. 2003; Faivre et al. 2003; Grether et al. 2004; McGraw and Ardia 2004). In this study, we supplemented males and females with various doses of carotenoids, and we activated the immune system with repeated injections of LPS. In agreement with the predictions, our results show that immune activation directly diverted carotenoids from the sexual signal by reducing the amount of circulating carotenoids in plasma. Interestingly, however, the effect of the immune activation did not depend on the amount of carotenoids available in the environment as shown by the nonsignificant carotenoid dose by immune treatment interaction. This result suggests that even at high doses, carotenoids are used up by the mounting of the immune response, and it confirms findings of a recent work where levels of plasma carotenoids of chickens were reduced by an LPS injection when birds were fed with a carotenoid-supplemented diet (Koutsos et al. 2003).

LPS is known to induce a wide-spectrum response initiated by the activation of macrophages and granulocytes such as neutrophils in mammals and heterophils in birds. Macrophages and granulocytes have a phagocytic activity and produce and release a cytotoxic compound, NO, which kills the invading pathogen (Klebanoff and Clark 1978). NO is a free radical (e.g., Fang et al. 2002), a very reactive compound that can also have a toxic effect toward the host cells and molecules (e.g., Allen 1997). Given the antioxidant activity of carotenoids, it is therefore possible that the LPS-caused reduction in carotenoid levels results not only from the modulation of the immune response but also from the scavenging of NO produced by the cells of the innate immune response.

We assessed the global antioxidant defenses of male and female zebra finches using a technique that evaluates the

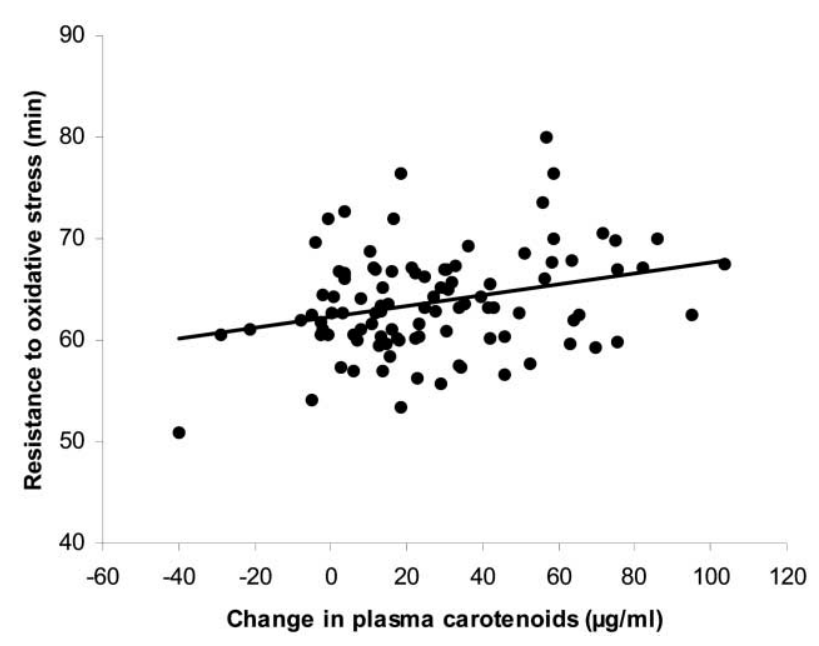

Figure 6: Relationship between resistance to oxidative stress at the end of the 4-week experimental period and change in plasma carotenoids. 
potential of red blood cells to resist a controlled free radical attack (Rojas Wahl et al. 1998; see also Alonso-Alvarez et al. 2004). All antioxidants in the blood are mobilized to fight off the radical attack, and therefore, this assay provides an overall appraisal of the antioxidant status. We found that the availability of carotenoids in the drinking water did not directly affect individual antioxidant status; however, birds with large amount of carotenoids in the plasma at the end of the experiment resisted more to the free radical attack. Several explanations could account for this apparent discrepancy. For instance, the variance in plasma carotenoids within the carotenoid dose groups suggests that the uptake, the assimilation, or the transport of carotenoids varied among individuals. This within-group variation might have masked any effect of carotenoid supplementation on stress resistance. However, an alternative hypothesis could be that healthy birds may be better at assimilating carotenoids and fighting free radicals, generating a positive correlation between plasma carotenoids and stress resistance.

\section{Acknowledgments}

We are very grateful to K. France for kindly providing the carotenoids (Oro Glo) used in this study. We thank the staff of the Station Biologique de Foljuif (École Normale Supérieure) and A. Besson for their help. Financial support was provided by the Ministère de la Recherche (Action Concertée Incitative Jeunes Chercheurs to G.S.) and the Université de Bourgogne (Bonus Qualité Recherche to G.D., M.G., J.P., and B.F.). C.A.-A. was funded by Ministerio de Educación, Cultura y Deporte (Spain).

\section{Literature Cited}

Ahmad, S. 1995. Oxidative stress and antioxidant defenses in biology. Chapman \& Hall, New York.

Allen, P. C. 1997. Nitric oxide production during Eimeria tenella infections in chickens. Poultry Science 76:810813.

Alonso-Alvarez, C., S. Bertrand, G. Devevey, J. Prost, B. Faivre, and G. Sorci. 2004. Increased susceptibility to oxidative stress as a proximate cost of reproduction. Ecology Letters 7:363-368.

Andersson, M. 1994. Sexual selection. Princeton University Press, Princeton, N.J.

Birkhead, T. R., F. Fletcher, and E. J. Pellatt. 1998. Sexual selection in the zebra finch Taeniopygia guttata: condition, sex traits and immune capacity. Behavioral Ecology and Sociobiology 44:179-191.

Blount, J. D., N. B. Metcalfe, T. R. Birkhead, and P. F. Surai. 2003. Carotenoid modulation of immune function and sexual attractiveness in zebra finches. Science 300:125-127.
Bright, A., and J. R. Waas. 2002. Effects of bill pigmentation and UV reflectance during territory establishment in blackbirds. Animal Behaviour 64:207-213.

Burley, N., and C. Coopersmith. 1987. Bill colour preferences of zebra finches. Ethology 76:133-151.

Burley, N. T., D. K. Price, and R. A. Zann. 1992. Bill color, reproduction and condition effects in wild and domesticated zebra finches. Auk 109:13-23.

Burton, G. W. 1989. Antioxidant actions of carotenoids. Journal of Nutrition 119:109-111.

Chew, B. P. 1993. Role of carotenoids in the immune response. Journal of Dairy Science 76:2804-2811.

Collins, S. A., and C. ten Cate. 1996. Does beak colour affect female preference in zebra finches? Animal Behaviour 52:105-112.

Craig, J. K., and C. J. Foote. 2001. Countergradient variation and secondary sexual color: phenotypic convergence promotes genetic divergence in carotenoid use between sympatric anadromous and nonanadromous morphs of sockeye salmon (Oncorhynchus nerka). Evolution 55:380-391.

Endler, J. A. 1980. Natural selection on color patterns in Poecilia reticulata. Evolution 34:76-91.

Espmark, Y., T. Amundsen, and G. Rosenqvist. 2000. Animal signals: signalling and signal design in animal communication. Tapir Academic, Trondheim.

Faivre, B., M. Préault, M. Théry, J. Secondi, B. Patris, and F. Cézilly. 2001. Breeding strategies and morphological characters in an urban population of blackbirds, Turdus merula. Animal Behaviour 61:969-974.

Faivre, B., A. Grégoire, M. Préault, F. Cézilly, and G. Sorci. 2003. Immune activation rapidly mirrored in a carotenoid-based secondary sexual trait. Science 300: 103.

Fang, Y.-Z., S. Yang, and G. Wu. 2002. Free radicals, antioxidants, and nutrition. Nutrition 18:872-879.

Girodon, F., D. Blache, A. L. Monget, M. Lombart, P. Brunet-Lecompte, J. Arnaud, M. J. Richard, and P. Galan. 1997. Effect of a two-year supplementation with low doses of antioxidant vitamins and/or minerals in elderly subjects on levels of nutrients and antioxidant defense parameters. Journal of the American College of Nutrition 16:357-365.

Grafen, A. 1990. Sexual selection handicapped by the Fisher process. Journal of Theoretical Biology 144:473516.

Grether, G. F., J. Hudon, and D. F. Millie. 1999. Carotenoid limitation of sexual coloration along an environmental gradient in guppies. Proceedings of the Royal Society of London B 266:1317-1322.

Grether, G. F., S. Kasahara, G. R. Kolluru, and E. L. Cooper. 2004. Sex-specific effects of carotenoid intake on the immunological response to allografts in guppies (Poe- 
cilia reticulata). Proceedings of the Royal Society of London B 271:45-49.

Hill, G. E. 1990. Female house finches prefer colourful males: sexual selection for a condition-dependent trait. Animal Behaviour 40:563-572.

- 1999. Is there an immunological cost to carotenoid-based ornamental coloration? American Naturalist 154:589-595.

Hudon, J. 1994. Showiness, carotenoids, and captivity: a comment on Hill (1992). Auk 111:218-221.

Janeway, C. A., and P. Travers. 1999. Immunobiology: the immune system in health and disease. 4th ed. Current Biology, London.

Johnstone, R. A. 1995. Sexual selection, honest advertisement and the handicap principle: reviewing the evidence. Biological Review 70:1-65.

Klebanoff, S. J., and R. A. Clark. 1978. The neutrophil: function and clinical disorders. North Holland, Amsterdam.

Kodric-Brown, A. 1989. Dietary carotenoids and male mating success in the guppy: an environmental component to female choice. Behavioral Ecology and Sociobiology 25:393-402.

Koutsos, E. A., C. C. Calvert, and K. C. Klasing. 2003. The effect of an acute phase response on tissue carotenoid levels of growing chickens (Gallus gallus domesticus). Comparative Biochemistry and Physiology A 135:635646.

Lesgards, J. F., P. Durand, M. Lassarre, P. Stocker, G. Lesgards, A. Lanteaume, M. Prost, and M.-P. LehucherMichel. 2002. Assessment of lifestyle effects on the overall antioxidant capacity of healthy subjects. Environmental Health Perspectives 110:479-487.

Lozano, G. A. 1994. Carotenoids, parasites, and sexual selection. Oikos 70:309-311.

McGraw, K. J., and D. R. Ardia. 2004. Carotenoids, immunocompetence, and the information content of sexual colors: an experimental test. American Naturalist 162:704-712.

McGraw, K. J., E. Adkins-Regan, and R. S. Parker. 2002.
Anhydrolutein in the zebra finch: a new, metabolically derived carotenoid in birds. Comparative Biochemistry and Physiology B 132:811-818.

McGraw, K. J., A. J. Gregory, R. S. Parker, and E. AdkinsRegan. 2003. Diet, plasma carotenoids, and sexual coloration in the zebra finch (Taeniopygia guttata). Auk 120:400-411.

Olson, V. A., and I. P. F. Owens. 1998. Costly sexual signals: are carotenoids rare, risky or required? Trends in Ecology \& Evolution 13:510-514.

Pieri, C., F. Moroni, and M. Marra. 1996. Food restriction increases the protection of erythorcytes against the hemolysis induced by peroxyl radicals. Mechanisms of Ageing and Development 87:15-23.

Poxton, I. R. 1995. Antibodies to lipopolysaccharide. Journal of Immunological Methods 186:1-15.

Rojas Wahl, R. U., L. Zeng, S. A. Madison, R. L. DePinto, and B. J. Shay. 1998. Mechanistic studies on the decomposition of water soluble azo-radical-initiators. Journal of Chemical Society, Perkin Transitions 29: 2009-2018.

SAS Institute. 2001. SAS/STAT software: changes and enhancements, version 8.2. SAS Institute, Cary, N.C.

Stocker, P., J. F. Lesgards, N. Vidal, F. Chalier, and M. Prost. 2003. ESR study of a biological assay on whole blood: antioxidant efficiency of various vitamins. Biochimica et Biophysica Acta 1621:1-8.

von Schantz, T. V., S. Bensch, M. Grahn, D. Hasselquist, and H. Wittzell. 1999. Good genes, oxidative stress and condition-dependent sexual signals. Proceedings of the Royal Society of London B 266:1-12.

Wiley, R. H. 1994. Errors, exaggeration, and deception in animal communication. Pages 157-189 in L. A. Real, ed. Behavioral mechanisms in evolutionary ecology. University of Chicago Press, Chicago.

Wynn, S. E., and T. Price 1993. Male and female choice in zebra finches. Auk 110:635-638.

Zahavi, A. 1975. Mate selection: a selection for a handicap. Journal of Theoretical Biology 53:205-214.

Associate Editor: Trevor Price 